\title{
Physiological and Morphological Traits and Competence for Carbon Sequestration of Several Green Roof Plants under a Controlled Environmental System
}

\author{
Takanori Kuronuma \\ Graduate School of Horticulture, Chiba University, 6-2-1 Kashiwa-no-ha, Kashiwa, Chiba, 277-0882, \\ Japan \\ Hitoshi Watanabe ${ }^{1}$ \\ Center for Environment, Health and Field Sciences, Chiba University, 6-2-1 Kashiwa-no-ha, \\ Kashiwa, Chiba, 277-0882, Japan
}

\begin{abstract}
AdDITIONAL INDEX words. irrigation, growth analysis, Sedum mexicanum, Sedum aizoon, Zoysia matrella, Ophiopogon japonicus

Abstract. The physiological and morphological traits of green roof plants are key to understanding the environmental benefits of green roofs. However, the comparative investigation of physiological and morphological traits of green roof plants is limited. Moreover, there have been few studies on the relevance of physiological and morphological traits and competence for carbon sequestration of green roof plants. In particular, Sedum L. species are generally regarded as crassulacean acid metabolism (CAM) plants, but several Sedum species are recognized as having an "inducible type of CAM." These plants are $C_{3}$ and $C_{4}$ plants, with the ability to switch their carbon metabolism to the CAM pathway. In the case of Sedum, the inducer of CAM is drought stress. This observation suggests that differences in water regimes result in physiological and morphological changes that may have a considerable effect on the environmental benefits of Sedum green roofs. The purpose of this study is to compare the physiological and morphological traits of four green roof plants and discuss the influence of these traits on their environmental benefits under a controlled environmental system. In addition, we attempted to clarify the relevance of physiological and morphological traits and competence for carbon sequestration in each plant using growth analysis. We used Sedum mexicanum Briton, Sedum aizoon L., Zoysia matrella (L.) Merr., and Ophiopogon japonicus (Thunb.) Ker Gawl. in this study, and only the two Sedum species were assigned treatments with different frequency of irrigation to investigate physiological and morphological responses and variation in carbon sequestration. The two Sedum species exhibited the $C_{3}$ photosynthetic pathway in wet and dry treatments, implying the inducible type of CAM. Morphological responses of the two Sedum species were significantly affected by the different frequencies of irrigation; plants responded to increases in below-ground resources (water and nutrients) with increased biomass allocation of leaves and stems. Owing to these physiological and morphological responses in the wet treatment, transpiration rates and competence for carbon sequestration [relative $C$ sequestration rate per whole-plant $C$ content $\left(\right.$ RGR $\left._{\mathrm{c}}\right)$ ] of the two Sedum species were higher than those of $Z$. matrella and $O$. japonicus. This result suggested that the cooling effect and carbon sequestration of Sedum in wet and increased nutrient conditions are equivalent to those observed in other plants. In addition, the net assimilation rate $\left(\mathrm{NAR}_{\mathrm{c}}\right)$ and leaf area ratio per whole-plant $\mathrm{C}$ content $\left(\mathrm{LAR}_{\mathrm{c}}\right)$ were significantly correlated with photosynthetic rates and biomass allocation. Thus, it became clear that growth analysis can reveal the relevance of physiological $\left(N A R_{c}\right)$ and morphological $\left(L A R_{c}\right)$ traits and $R_{G}$ G. Our results will serve as a baseline of the physiological and morphological traits and carbon sequestration of green roof plants and contribute to more suitable design and maintenance of vegetation in green roofs.
\end{abstract}

The green roof is known to be a beneficial technology in urban environments. Some of the benefits include cooling and insulation of buildings (Sailor, 2008; Wong et al., 2003), mitigation of the urban heat-island effect (Susca et al., 2011), stormwater management (Getter et al., 2007; Villarreal and Bengtsson, 2005), carbon sequestration and air pollution reduction (Getter et al., 2009; Yang et al., 2008), and habitat provision for other organisms (Kadas, 2006). Owing to these environmental benefits, the green roof has been adopted in many countries. These benefits depend on the presence of living plants and the growing medium. For example, the boundary layer of air over the roof is cooled by evapotranspiration,

Received for publication 16 Aug. 2016. Accepted for publication 9 Sept. 2016. ${ }^{1}$ Corresponding author. E-mail: hwatanabe@faculty.chiba-u.jp. shading from plants, and the trapping of cool air by the vegetation layer (Dimoudi and Nikolopoulou, 2003; Solecki et al., 2006). In addition, air pollution is reduced through plant photosynthesis and trapping of the gases by vegetation and soil layers (Garland, 1977). Consequently, the physiological and morphological traits of the plants are key to understanding the environmental benefits of green roofs. However, the comparative investigation of physiological and morphological traits of green roof plants is limited (Lundholm et al., 2015). Moreover, there have been few studies examining the relevance of physiological and morphological traits and competence for carbon sequestration in green roof plants.

Warm-season turfgrasses and Sedum species are the most common vegetation in Japan. Green roofs composed of warmseason turfgrasses or other perennials are generally installed 
with irrigation systems to prevent drought stress. In contrast, Sedum green roofs are not always installed with irrigation because these plants can adapt to periodic drought. They are regarded as CAM plants whose stomata remain closed during the day, with gas exchange occurring at night (VanWoert et al., 2005). This physiological pathway plays a crucial role in the plant's response to drought stress; other CAM plants have also been investigated for utilization in green roofs ( $\mathrm{Lin}$ and Lin, 2011). In addition, several Sedum species are recognized as having an "inducible type of CAM" (Gravatt and Martin, 1992; Lee and Griffiths, 1987). They are $C_{3}$ and $C_{4}$ plants with the ability to switch their carbon metabolism to the CAM pathway. In the case of Sedum, the inducer of CAM is drought stress (Sayed, 2001). This observation suggests that differences in water regimes result in physiological and morphological changes that may have a considerable effect on the environmental benefits of Sedum green roofs (e.g., carbon sequestration, air pollution reduction, and cooling effects). Further, although a Sedum green roof is likely to be exposed to drought conditions, the substrate may be wet during the rainy season in southeast Asian countries (Chen, 2013). Van Mechelen et al. (2015) also suggested that irrigation is necessary on green roofs in (semi)-arid climates for the survival and success of extensive green roof plantings. Therefore, it is necessary to investigate the physiological and morphological responses of Sedum to various water conditions resulting from different maintenance practices and climates.

The purpose of this study is to compare the physiological and morphological traits of several green roof plants and discuss the influence of these traits on their environmental benefits. In addition, we attempted to clarify the relevance of physiological and morphological traits and competence for carbon sequestration in each plant using growth analysis. In particular, Sedum species were assigned different water regimes to investigate the physiological and morphological responses and variation in carbon sequestration.

\section{Materials and Methods}

\section{Plant material}

We focused on groundcover herbaceous green roof plants for comparison of physiological and morphological traits; thus, $S$. mexicanum, S. aizoon, Z. matrella, and O. japonicus 'TamaRyu' were selected for this study. Although these species are widely distributed in Japan, the photosynthetic pathway of the two Sedum species is not well understood. Zoysia matrella, a warm-season turfgrass and $\mathrm{C}_{4}$ plant, is one of the most common green roof plants in Japan. Ophiopogon japonicus is an evergreen perennial.

All plants in this study were propagated as cuttings in plug flats (128 cells/tray) filled with seedling propagation medium (Metro Mix; Sun Gro Horticulture, Agawam, MA). After $\approx 1$ month, plugs were planted in $0.2-\mathrm{L}$ polyethylene pots $\left(44 \mathrm{~cm}^{2}\right)$ filled to a depth of $5 \mathrm{~cm}$ with commercial artificial soil for green roofs (114 mg. $\mathrm{kg}^{-1} \mathrm{NO}_{3}-\mathrm{N}, 323 \mathrm{mg} \cdot \mathrm{kg}^{-1} \mathrm{NH}_{4}-\mathrm{N}, 159 \mathrm{mg} \cdot \mathrm{kg}^{-1}$ $\mathrm{P}_{2} \mathrm{O}_{5}, 32 \mathrm{mg} \cdot \mathrm{kg}^{-1} \mathrm{~K}_{2} \mathrm{O}, 41 \mathrm{mg} \cdot \mathrm{kg}^{-1} \mathrm{CaO}$, and $\left.2 \mathrm{mg} \cdot \mathrm{kg}^{-1} \mathrm{MgO}\right)$. The artificial soil composition was $75 \%$ perlite, $22 \%$ bark and peat, and 3\% zeolite. Bulk density of the substrate was 0.22 $\mathrm{g} \cdot \mathrm{mL}^{-1}$, and three-phase distribution was solid phase of $37.0 \%$, liquid phase of $49.4 \%$, and gas phase of $13.6 \%$. Because it is lightweight and has high water retention capacity, such green roof soils, which mainly consist of a perlite, are widely used for extensive green roofs in Japan. The plants were placed in a totally controlled environmental system (phytotron) and grown about 3 weeks under the following conditions: $25{ }^{\circ} \mathrm{C}$ (light period) and $20{ }^{\circ} \mathrm{C}$ (dark period), $65 \% \pm 10 \%$ humidity, $400 \mu \mathrm{L} \cdot \mathrm{L}^{-1} \mathrm{CO}_{2}$ concentration, $14 \mathrm{~h}$ light $\left(200-250 \mu \mathrm{mol} \cdot \mathrm{m}^{-2} \cdot \mathrm{s}^{-1}\right)$, and $10 \mathrm{~h}$ dark.

\section{Comparative study of physiological traits}

EXPerimental Design. To investigate the photosynthetic pathway of the two Sedum species in wet and dry conditions, individuals of the two Sedum species were assigned randomly to wet or dry treatments and acclimatized to each treatment for 3 weeks. Plants in the wet treatment were watered every day, and plants receiving the dry treatment were watered once per week. Zoysia matrella and $O$. japonicus only received the wet treatment, in accordance with general cultivation practice. In this study, to reduce the influence of nutrient-poor conditions on plant growth, an irrigation system supplied not water but nutrient solution $\left(72 \mu \mathrm{L} \cdot \mathrm{L}^{-1} \mathrm{NO}_{3}-\mathrm{N}, 11 \mu \mathrm{L} \cdot \mathrm{L}^{-1} \mathrm{NH}_{4}-\mathrm{N}, 100\right.$ $\mu \mathrm{L} \cdot \mathrm{L}^{-1} \mathrm{P}_{2} \mathrm{O}_{5}, 167 \mu \mathrm{L} \cdot \mathrm{L}^{-1} \mathrm{~K}_{2} \mathrm{O}, 71 \mu \mathrm{L} \cdot \mathrm{L}^{-1} \mathrm{CaO}$, and $17 \mu \mathrm{L} \cdot \mathrm{L}^{-1}$ $\mathrm{MgO}$ ) for $30 \mathrm{~min}$ by bottom watering in every treatment. All studies were carried out in the phytotron.

Photosynthetic pathway of $\boldsymbol{S}$. Mexicanum and $\boldsymbol{S}$. aizoon. The photosynthetic and transpiration rates of five plants per treatment were measured for $4 \mathrm{~h}(2 \mathrm{~h}$ light period, $2 \mathrm{~h}$ dark period) using a photosynthesis system (LI-6400; LI-COR, Lincoln, NE) with an light-emitting diode light source. Measurement conditions were as follows: $25^{\circ} \mathrm{C}$ (light) and $20{ }^{\circ} \mathrm{C}$ (dark), $50 \% \pm 10 \%$ humidity, $400 \mu \mathrm{L} \cdot \mathrm{L}^{-1} \mathrm{CO}_{2}$ concentration, and $1000 \mu \mathrm{mol} \cdot \mathrm{m}^{-2} \cdot \mathrm{s}^{-1}$ photosynthetic photon flux density (assumed roof conditions). The soil water content for individuals in the dry treatment was investigated after irrigation $(0,1$, 2, 3, 4, 5, and $6 \mathrm{~d}$ ) using a soil moisture sensor (EC-5 and ProCheck; Decagon, Pullman, WA).

COMPARISON OF PHOTOSYNTHETIC AND TRANSPIRATION RATES IN WET TREATMENT. For individuals of the four species in the wet treatment, photosynthetic and transpiration rates were measured at 15,25 , and $35^{\circ} \mathrm{C}$, which are assumed roof conditions. Other measurement conditions were the same as above. Photosynthetic water use efficiency $\left[\mathrm{WUE}_{\mathrm{ph}}\right.$ (photosynthetic rate/transpiration rate)] was calculated for each plant.

\section{Comparative study of morphological traits and competence for carbon sequestration}

EXPERIMENTAL DESIGN. To examine morphological traits and carbon sequestration, we investigated biomass allocation and whole-plant carbon sequestration in the phytotron.

In all four species, 15 total pots per species were selected at random (three pots were chosen at 0,1 , and $2 \mathrm{~d}$, and six pots were selected at $3 \mathrm{~d}$ after the start of the experiment). After these samples were selected, the Sedum species were divided into wet, dry, and nonirrigation treatments. Plants in all treatments were irrigated at the start of the experiment $(0 \mathrm{~d})$. After this irrigation, the nonirrigation treatment was never irrigated. Wet and dry treatments and the irrigation system (supplied nutrient solution) were the same as above, but there was no irrigation in the wet treatment for 1-3 d. Zoysia matrella and $O$. japonicus plants only received the wet treatment.

Three pots were randomly harvested once per week for 4-6 weeks after the start of the experiment (28, 35, and $42 \mathrm{~d}$ ), and the remaining six pots were harvested at the end of the experiment (49 d). We regarded these 15 total pots (at 28, 35, 
42 , and 49 d) as the result of treatment. For all samples, roots were removed from the soil and washed with distilled water.

MORPHOLOGICAL RESPONSES TO WATER REGIMES OF TWO SEDUM SPECIES AND COMPARISON TO $Z$. MATRELLA AND $O$. JAPONICUS. Plants were divided into leaves, stems, roots, and flowers and dried at $70{ }^{\circ} \mathrm{C}$ for $72 \mathrm{~h}$. Before the leaves were dried, they were scanned (LP-A500; Epson, Suwa, Japan) and image analysis software ImageJ (Schneider et al., 2012) was used to measure the leaf area and greenness of leaves. We calculated the leaf area index [LAI (leaf area per $44 \mathrm{~cm}^{2}$ )], and described greenness of leaves with $\mathrm{G} / \mathrm{R}$, which is related to chlorophyll content (Adamsen et al., 1999). Biomass allocation was analyzed using five indices: leaf mass fraction [LMF (leaf mass per whole-plant mass)], stem mass fraction [SMF (stem mass per whole-plant mass)], root mass fraction [RMF (root mass per whole-plant mass)], flower mass fraction [FMF (flower mass per whole-plant mass)], and specific leaf area [SLA (leaf area per leaf mass)].

QUANTITATIVE ANALYSIS OF CARBON SEQUESTRATION AND THE INFLUENCE OF PHYSIOLOGICAL AND MORPHOLOGICAL TRAITS USING GROWTH ANALYSIS. Plants carbon concentration was measured using an organic elemental analyzer (2400 SeriesII CHNS/O System; PerkinElmer, Waltham, MA); whole-plant carbon content was quantified by multiplication of carbon concentration and whole-plant mass.

Growth analysis is a simple model that associates a plant's relative growth rate (RGR) with physiological [net assimilation rate (NAR)] and morphological [leaf area ratio (LAR)] traits (Lambers et al., 1989), which have a mathematical relationship $(\mathrm{RGR}=\mathrm{NAR} \times \mathrm{LAR})$. In addition, growth analysis provides a more informative comparison of a plant's relative performance because it can reduce the influence of differences in the initial size and mass among the experimental plants (Hunt, 1982). This model is generally applied to dry weights, but this experiment focused on whole-plant carbon content because our goal was to examine the relevance of physiological and morphological traits and carbon sequestration in each plant. Thus, we carried out growth analysis using a functional approach (Hunt, 1982) and calculated relative C sequestration rate per whole-plant $\mathrm{C}$ content $\left(\mathrm{RGR}_{\mathrm{c}}\right), \mathrm{NAR}_{\mathrm{c}}$, and $\mathrm{LAR}$ per whole-plant $\mathrm{C}$ content $\left(\mathrm{LAR}_{\mathrm{c}}\right)$. We used $\mathrm{RGR}_{\mathrm{c}}$ as the measure of the ability to sequester carbon. Moreover, for the two Sedum species, growth response coefficients (GRC) of $\mathrm{NAR}_{\mathrm{c}}$ and $\mathrm{LAR}_{\mathrm{c}}$ (comparisons: wet and dry, wet and nonirrigation, and dry and nonirrigation) were calculated. The GRC values of NAR and LAR sum to 1.0 , indicating the relative contribution
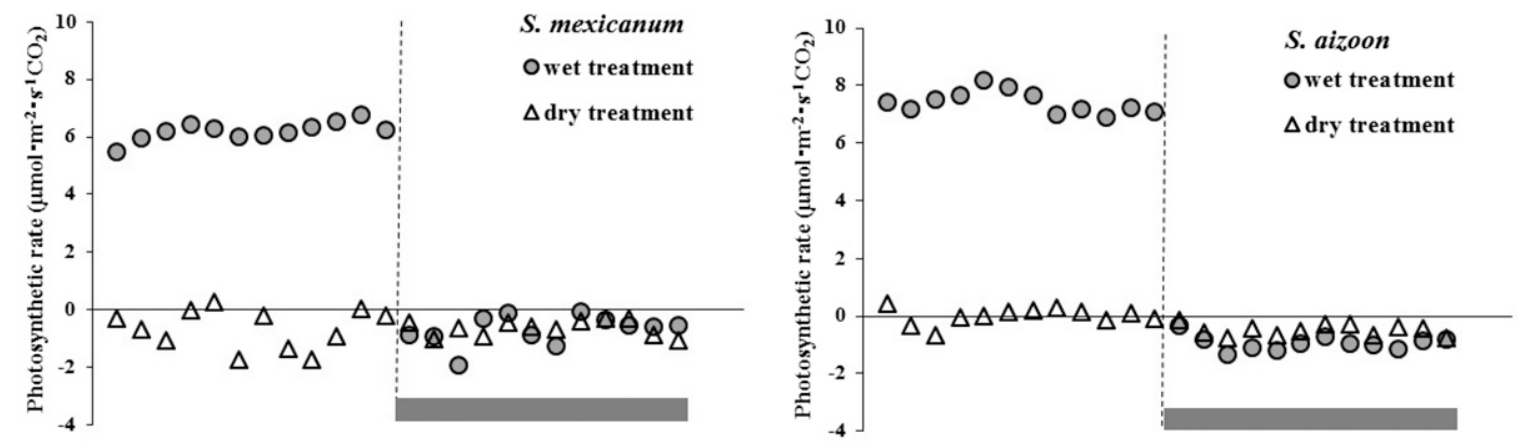

Fig. 1. Representative values of sequential photosynthetic rates of two Sedum species (Sedum mexicanum and Sedum aizoon) for $4 \mathrm{~h}$ in wet treatment (plants supplied nutrient solution every day) and dry treatment (plants supplied nutrient solution once per week) at $6 \mathrm{~d}$ after irrigation. Black bars indicate dark period.
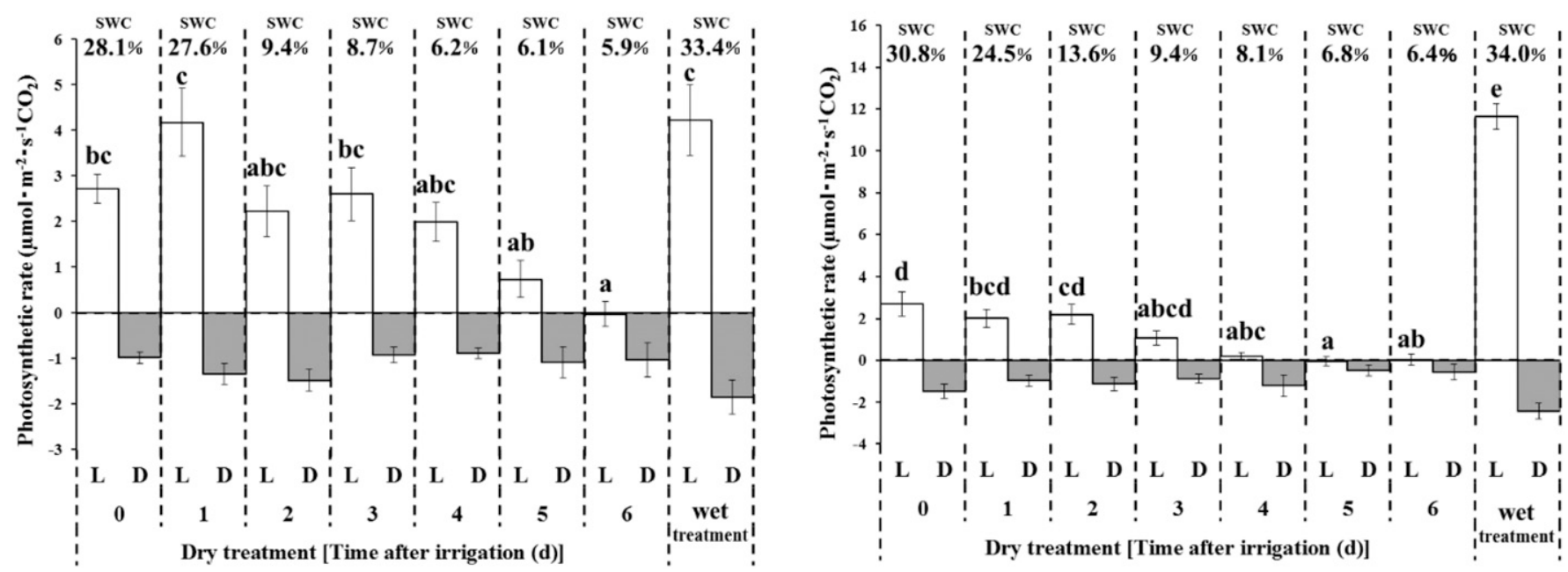

Fig. 2. Mean values for photosynthetic rate of two Sedum species [(A) Sedum mexicanum, (B) Sedum aizoon] in dry (plants supplied nutrient solution once per week) and wet treatments (plants supplied nutrient solution every day). L and D indicate light and dark periods. SWC is the mean soil water content. Means \pm SE are presented $(\mathrm{n}=5)$. Significant differences among means are indicated by different letters based on Tukey-b test at $P<0.05$. 
of those parameters to a change in RGR (Poorter and Nagel, 2000; Poorter and Van der Werf, 1998). For example, if GRC $_{\text {LAR }}$ is 1 , a change in RGR is attributed only to a change in LAR. In other words, $\mathrm{GRC}_{\mathrm{NARc}}$ and $\mathrm{GRC}_{\mathrm{LARc}}$ indicate the influence of physiological and morphological changes on competence for carbon sequestration.

\section{Statistical analysis}

Data were analyzed using IBM SPSS Statistics (version 22.0; IBM Japan, Tokyo, Japan). Analysis of variance was used to assess the effects of treatments and the plant species. Differences in mean values were assessed with Student's $t$ test or multiple comparisons [Tukey-b (homoscedasticity assumed) or Dinnett-T3 (homoscedasticity not assumed)].

\section{Results and Discussion}

\section{Comparative study of physiological traits}

Photosynthetic pathway of $S$. Mexicandm and $S$. aizoon. Individuals of $S$. mexicanum and $S$. aizoon in the wet treatment exhibited $\mathrm{CO}_{2}$ uptake only during the light period and no dark period $\mathrm{CO}_{2}$ uptake in any of the samples (Fig. 1). In the dry treatment, $S$. mexicanum and $S$. aizoon did not exhibit $\mathrm{CO}_{2}$ uptake during light and dark periods at $6 \mathrm{~d}$ after irrigation, similar to the photosynthetic pathway of several Sedum species which had an inducible type of CAM under drought conditions (Gravatt and Martin, 1992; Lee and Griffiths, 1987). The mean photosynthetic rate during the light period under the wet treatment was significantly higher than that under the dry treatment (Student's $t$ test at $P<0.05$ ). Thus, these results imply that $S$. mexicanum and $S$. aizoon have an inducible type of CAM.

Soil water content in the dry treatment was below $10 \%$ at 2 to $6 \mathrm{~d}$ after irrigation; however, $S$. mexicanum displayed the $\mathrm{C}_{3}$ photosynthetic pathway (Fig. 2A). Moreover, although the frequency of water and nutrient supply under the dry treatment was lower than that under the wet treatment, photosynthetic and transpiration rates at 0 to $4 \mathrm{~d}$ after irrigation were not significantly different from those in the wet treatment (Fig. 2A; Table 1). Sedum aizoon also exhibited the $\mathrm{C}_{3}$ photosynthetic pathway in the dry treatment (Fig. 2B), but the photosynthetic and transpiration rates were significantly lower than those in the wet treatment (Fig. 2B; Table 1). In green roofs, some studies suggested that Sedum species have exhibited the $C_{3}$ photosynthetic pathway (Butler and Orians, 2011; Durhman et al., 2006). Our results are consistent with this photosynthetic response occurring in green roofs.

COMPARISON OF PHOTOSYNTHETIC AND TRANSPIRATION RATES IN WET TREATMENT. The photosynthetic rate of $S$. mexicanum at all temperatures was significantly lower than that of $Z$. matrella and not significantly different from that of $O$. japonicus (Fig. 3). Photosynthetic rates of $S$. aizoon were significantly higher than those of $O$. japonicus and similar to those of $Z$. matrella except at $35{ }^{\circ} \mathrm{C}$ (Fig. 3). Sedum species in the wet treatment exhibited similar photosynthetic rates to those of other green roof plants, including the $\mathrm{C}_{4}$ plant, Z. matrella. However, the photosynthetic rate of $\mathrm{C}_{4}$ plants is generally higher at high temperatures, so $Z$. matrella should show the highest photosynthetic rate at $35^{\circ} \mathrm{C}$.

Transpiration rates of the two Sedum species at each temperature were higher than that of $Z$. matrella, and there were significant differences from transpiration rates of $O$. japonicus at 15 and $25^{\circ} \mathrm{C}$ (Table 2). $\mathrm{WUE}_{\mathrm{ph}}$ of the two Sedum species was lower than that of $Z$. matrella and $O$. japonicus (Table 2). Although CAM plants typically have high WUE and low transpiration rates (Nobel, 1991), the two Sedum species in the wet treatment had distinctively lower WUE and higher transpiration rates than did other green roof plants. This result supports the $\mathrm{C}_{3}$ pathway being used for photosynthesis.

Previous research has suggested that evapotranspiration is the most important contributor toward the cooling effect in green roofs (Feng et al., 2010; Oberndorfer et al., 2007; Takakura et al., 2000). In addition, some studies reported that irrigation has enhanced the cooling effect (Blanusa et al., 2013;

Table 1. Mean values $(\mathrm{n}=5)$ for transpiration rates of two Sedum species (Sedum mexicanum and Sedum aizoon) in dry treatment (plants supplied nutrient solution once per week) and wet treatment (plants supplied nutrient solution every day).

\begin{tabular}{lcclll}
\hline & Time after & \multicolumn{2}{c}{ S. mexicanum } & \multicolumn{2}{c}{ S. aizoon } \\
\cline { 2 - 6 } Treatment & $\begin{array}{c}c \\
\text { irrigation }(\mathrm{d})\end{array}$ & \multicolumn{2}{c}{$\left[\right.$ mean $\left.\pm \mathrm{SE}\left(\mathrm{mmol} \cdot \mathrm{m}^{-2} \cdot \mathrm{s}^{-1} \mathrm{H}_{2} \mathrm{O}\right)\right]$} \\
\hline Dry & 0 & $1.11 \pm 0.15$ & $\mathrm{c}^{\mathrm{z}}$ & $0.72 \pm 0.17$ & $\mathrm{ABC}^{\mathrm{y}}$ \\
& 1 & $1.30 \pm 0.21$ & $\mathrm{c}$ & $0.44 \pm 0.07$ & $\mathrm{C}$ \\
& 2 & $0.98 \pm 0.23$ & $\mathrm{bc}$ & $0.28 \pm 0.03$ & $\mathrm{C}$ \\
& 3 & $0.86 \pm 0.20$ & $\mathrm{bc}$ & $0.26 \pm 0.04$ & $\mathrm{BC}$ \\
& 4 & $0.63 \pm 0.11$ & $\mathrm{abc}$ & $0.04 \pm 0.02$ & $\mathrm{~A}$ \\
& 5 & $0.31 \pm 0.09$ & $\mathrm{ab}$ & $0.01 \pm 0.03$ & $\mathrm{~A}$ \\
Wet & 6 & $0.14 \pm 0.11$ & $\mathrm{a}$ & $0.07 \pm 0.03$ & $\mathrm{AB}$ \\
& - & $0.96 \pm 0.21$ & $\mathrm{bc}$ & $2.78 \pm 0.24$ & $\mathrm{D}$ \\
\hline
\end{tabular}

${ }^{\mathrm{z}}$ Significant differences among means are indicated by different letters based on Tukey-b test at $P<0.05$.

${ }^{y}$ Significant differences among means are indicated by different letters based on Dunnett-T3 at $P<0.05$.

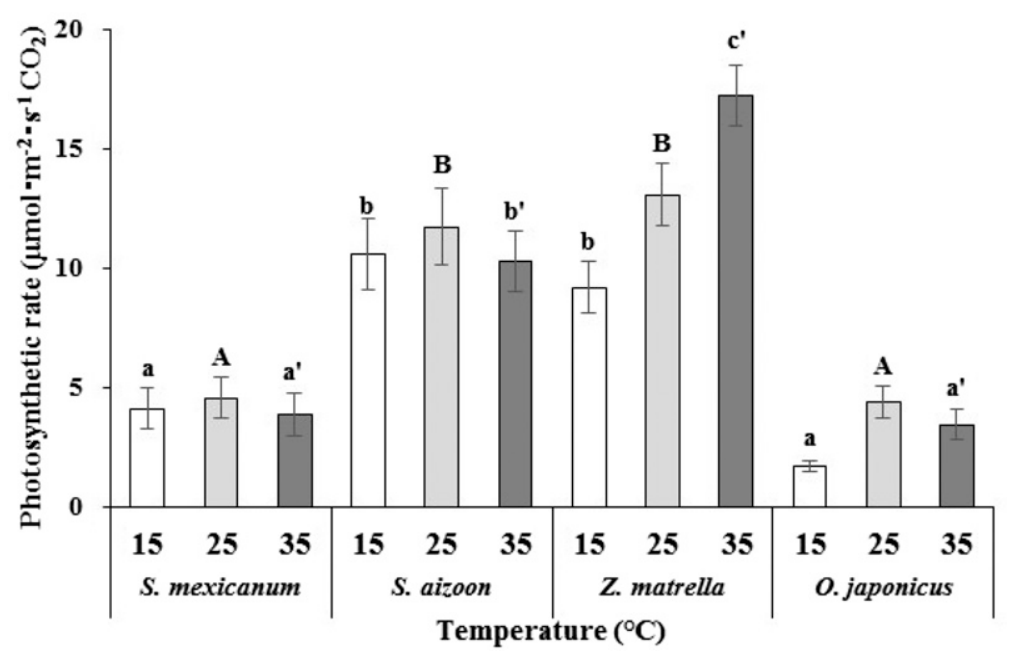

Fig. 3. Means values for photosynthetic rates of four green roof plants (Sedum mexicanum, Sedum aizoon, Zoysia matrella, and Ophiopogon japonicus) in wet treatment (plants supplied nutrient solution every day) at each temperature $\left(15,25\right.$, and $\left.35^{\circ} \mathrm{C}\right)$. Means \pm SE are presented $(n=5)$. Significant differences among means are indicated by different letters based on Tukey-b test at $P<0.05$. 


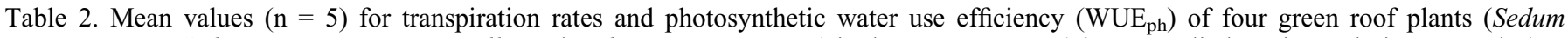
mexicanum, Sedum aizoon, Zoysia matrella, and Ophiopogon japonicus) in the wet treatment (plants supplied nutrient solution every day) at each temperature $\left(15,25\right.$, and $\left.35^{\circ} \mathrm{C}\right)$.

\begin{tabular}{|c|c|c|c|c|c|c|c|c|c|c|c|c|}
\hline \multirow{4}{*}{$\frac{\text { Species }}{\text { S. mexicanum }}$} & \multicolumn{6}{|c|}{ Transpiration rate } & \multicolumn{6}{|c|}{ WUE $_{\mathrm{ph}}$} \\
\hline & \multicolumn{6}{|c|}{$\left[\right.$ mean $\left.\pm \operatorname{SE}\left(\mathrm{mmol} \cdot \mathrm{m}^{-2} \cdot \mathrm{s}^{-1} \mathrm{H}_{2} \mathrm{O}\right)\right]$} & \multicolumn{6}{|c|}{$\left[\right.$ mean $\left.\pm \mathrm{SE}\left(\mu \mathrm{mol} \cdot \mathrm{m}^{-2} \cdot \mathrm{s}^{-1} \mathrm{CO}_{2} / \mathrm{mmol} \cdot \mathrm{m}^{-2} \cdot \mathrm{s}^{-1} \mathrm{H}_{2} \mathrm{O}\right)\right]$} \\
\hline & \multicolumn{2}{|c|}{$15^{\circ} \mathrm{C}$} & \multicolumn{2}{|c|}{$25^{\circ} \mathrm{C}$} & \multicolumn{2}{|c|}{$35^{\circ} \mathrm{C}$} & \multicolumn{2}{|c|}{$15^{\circ} \mathrm{C}$} & \multicolumn{2}{|c|}{$25^{\circ} \mathrm{C}$} & \multicolumn{2}{|c|}{$35^{\circ} \mathrm{C}$} \\
\hline & $1.2 \pm 0.2$ & $\mathrm{bc}^{\mathrm{z}}$ & $1.6 \pm 0.2$ & $\mathrm{~B}^{\mathrm{z}}$ & $2.3 \pm 0.5$ & $a^{\prime} b^{\prime z}$ & $3.8 \pm 0.8$ & $\mathrm{a}^{\mathrm{z}}$ & $2.8 \pm 0.4$ & $\mathrm{~A}^{\mathrm{z}}$ & $1.9 \pm 0.3$ & $\mathrm{a}^{\prime \mathrm{y}}$ \\
\hline Z. matrella & $0.7 \pm 0.1$ & $\mathrm{ab}$ & $1.2 \pm 0.1$ & B & $2.1 \pm 0.1$ & $a^{\prime} b^{\prime}$ & $12.9 \pm 0.6$ & $\mathrm{~b}$ & $11.5 \pm 1.0$ & $\mathrm{C}$ & $8.3 \pm 1.0$ & $\mathrm{~b}^{\prime}$ \\
\hline O. japonicus & $0.2 \pm 0.0$ & $\mathrm{a}$ & $0.8 \pm 0.1$ & A & $1.0 \pm 0.2$ & $a^{\prime}$ & $9.6 \pm 2.3$ & $a b$ & $6.1 \pm 1.1$ & $\mathrm{AB}$ & $3.8 \pm 0.9$ & $\mathrm{a}^{\prime}$ \\
\hline
\end{tabular}

${ }^{\mathrm{z}}$ Significant differences among means are indicated by different letters based on Dunnett-T3 at $P<0.05$.

${ }^{\mathrm{y}}$ Significant differences among means are indicated by different letters based on Tukey-b test at $P<0.05$.

Table 3. Mean values $(n=6)$ for dry weight, leaf area index $(\mathrm{LAI})$, and the ratio of green to red pixels treatments were watered every day in an image of leaves (G/R) of two Sedum species (Sedum mexicanum and Sedum aizoon) in wet and not analyzed soil water content, treatment (plants supplied nutrient solution every day), dry treatment (plants supplied nutrient this result suggests that plants in the solution once per week), and nonirrigation treatment [plants only supplied nutrient solution at the start of the experiment ( $0 \mathrm{~d})$ ] at the end of the experiment ( $49 \mathrm{~d})$, and those of two green roof plants (Zoysia matrella and Ophiopogon japonicus) in the wet treatment.

\begin{tabular}{llccrccc}
\hline Species & Treatment & Dry wt $[$ mean \pm SE $(\mathrm{g})]$ & LAI $($ mean $\pm \mathrm{SE})$ & \multicolumn{2}{c}{ G/R (mean $\pm \mathrm{SE})$} \\
\hline S. mexicanum & Wet & $9.1 \pm 0.4$ & $\mathrm{C}^{\mathrm{z}}$ & $50.8 \pm 1.3$ & $\mathrm{C}^{\mathrm{y}}$ & $1.16 \pm 0.00$ & $\mathrm{~d}^{\prime \mathrm{y}}$ \\
& Dry & $2.9 \pm 0.1$ & $\mathrm{~B}$ & $11.3 \pm 0.5$ & $\mathrm{~B}$ & $1.15 \pm 0.00$ & $\mathrm{c}^{\prime}$ \\
& Nonirrigation & $0.7 \pm 0.0$ & $\mathrm{~A}$ & $1.3 \pm 0.1$ & $\mathrm{~A}$ & $1.09 \pm 0.00$ & $\mathrm{a}^{\prime}$ \\
S. aizoon & Wet & $9.5 \pm 0.5$ & $\mathrm{c}^{\mathrm{y}}$ & $15.7 \pm 0.7$ & $\mathrm{c}^{\mathrm{y}}$ & $1.21 \pm 0.00$ & $\mathrm{e}^{\prime}$ \\
& Dry & $2.2 \pm 0.1$ & $\mathrm{~b}$ & $4.4 \pm 0.1$ & $\mathrm{~b}$ & $1.12 \pm 0.00$ & $\mathrm{~b}^{\prime}$ \\
& Nonirrigation & $0.7 \pm 0.0$ & $\mathrm{a}$ & $1.1 \pm 0.0$ & $\mathrm{a}$ & $1.12 \pm 0.01$ & $\mathrm{~b}^{\prime}$ \\
Z. matrella & Wet & $7.5 \pm 0.5$ & & $17.3 \pm 0.3$ & & $1.20 \pm 0.00$ & $\mathrm{e}^{\prime}$ \\
O. japonicus & Wet & $1.9 \pm 0.3$ & & $3.2 \pm 0.4$ & & $1.15 \pm 0.00$ & $\mathrm{c}^{\prime}$
\end{tabular}

${ }^{\mathrm{z}}$ Significant differences among means are indicated by different letters based on Tukey-b test at $P<0.05$. ${ }^{y}$ Significant differences among means are indicated by different letters based on Dunnett-T3 at $P<0.05$.

Lin and Lin, 2011; Solecki et al., 2006). Therefore, our results indicate that the cooling effect of Sedum in wet and increased nutrient conditions may be equivalent to that of other plants from the standpoint of evapotranspiration. Moreover, even Sedum roofs with a low frequency of irrigation or rain events may improve the thermal load because Sedum in the dry treatment exhibited the $\mathrm{C}_{3}$ pathway.

\section{Comparative study of morphological traits and competence for carbon sequestration}

Plant status. There was no significant difference in initial dry weight $( \pm \mathrm{SE})$ between $S$. mexicanum $(0.52 \pm 0.03 \mathrm{~g}), S$. aizoon $(0.55 \pm 0.03 \mathrm{~g})$, and $Z$. matrella $(0.50 \pm 0.04 \mathrm{~g})$. At the end of the experiment, the two Sedum species had significant differences in dry weight and LAI among the treatments (Table 3). The dry weight of $Z$. matrella was less than that of Sedum in the wet treatment. Ophiopogon japonicus had a lower dry weight than Sedum in the dry treatments, although its initial dry weight $(0.66 \pm 0.02 \mathrm{~g})$ was significantly higher than that of the other species (Tukey-b test at $P<0.05$ ). Under our experimental conditions, the LAI of $S$. mexicanum in the wet treatment was much larger than that in the dry treatment and that of the other species (Table 3).

$\mathrm{G} / \mathrm{R}$ of $S$. mexicanum declined significantly with decreased frequency of irrigation (Table 3). In contrast, S. aizoon showed no difference in $\mathrm{G} / \mathrm{R}$ between dry and nonirrigation treatments. However, all species and treatments had a $\mathrm{G} / \mathrm{R}$ greater than 1.0 , which indicates all plants have not withered and are still green. Moreover, although $Z$. matrella and $O$. japonicus in the wet wet treatment did not experience drought or waterlogging stress, which greatly affect plant growth.

MoRPhOLOGICAL RESPONSES TO Water Regimes of two Sedum SPECIES AND COMPARISON WITH $Z$. MATRELLA AND O. JAPONICUS. The morphological responses of all four species at $28,35,42$, and $49 \mathrm{~d}$ are presented in Table 4. All morphological traits of $S$. mexicanum were significantly affected by the difference in frequency of irrigation. LMF, SMF, and SLA in the wet treatment were significantly higher than those in the nonirrigation treatment, and RMF in the wet treatment was significantly lower than that in dry and nonirrigation treatments. The morphological response of $S$. aizoon was similar to that of $S$. mexicanum, but there was no significant difference in treatments on SLA. The only species that flowered during the experiment was $S$. aizoon (wet treatment: flowering rate $=15 / 15, \mathrm{FMF}=0.14 \pm 0.02$; dry treatment: flowering rate $=5 / 15, \mathrm{FMF}=0.013 \pm 0.006$ ). It is well documented that plants respond to a decrease in belowground resources (e.g., water, nutrients) with increased biomass allocation to roots (Poorter and Nagel, 2000) which is consistent with the results of LMF, SMF, and RMF in this study.

LMF of the two Sedum species in wet and dry treatments was significantly higher than that of Z. matrella and O. japonicas (Table 4). The SMF and RMF results clearly demonstrate that $Z$. matrella allocated significantly more biomass to stems, and $O$. japonicas allocated significantly more biomass to roots. SLA of the Z. matrella and O. japonicus exhibited similar values to that of $S$. mexicanum in the nonirrigation treatment, and SLA of S. mexicanum in wet and dry treatments were significantly higher than that of the other species.

In green roofs, LAI and SLA were evaluated as predictors of environmental benefits (Lundholm et al., 2015; Takakura et al., 2000). There may be differences in growth condition and stage between this experiment and actual green roofs. However, results of the current study clearly indicate that these morphological indices of the two Sedum species significantly change with changes in below-ground resources (water and nutrients), which suggest that appropriate water and nutrient management improves the environmental benefits of Sedum green roofs. In 
addition, as shown by the differing Table 4. Mean values $(n=15)$ for biomass allocation as measured by leaf mass fraction $(\mathrm{LMF})$, stem changes in SLA of the two Sedum species, species have individual traits and respond differently to belowground resources. From the standpoint of morphological traits of leaves, $S$. mexicanum may be more appropriate for a green roof based on this study. Thus, it is necessary to consider the morphological traits of the plants involved to design a more effective green roof.

QUANTITATIVE ANALYSIS OF CARBON S. aizoon (Sedum mexicanum and Sedum aizoon) in wet treatment (plants supplied nutrient solution every day), dry treatment (plants supplied nutrient solution once per week), and nonirrigation treatment [plants only supplied nutrient solution at the start of the experiment $(0 \mathrm{~d})]$ at the $28,35,42$, and $49 \mathrm{~d}$ after the start of experiment, and those of two green roof plants (Zoysia matrella and Ophiopogon japonicus) in the wet treatment.

SEQUESTRATION AND THE INFLUENCE OF PHYSIOLOGICAL AND MORPHOLOGICAL TRAITS USING GROWTH ANALYSIS. Car- Z. matrella Wet bon concentration of the two Sedum O.japonicus We

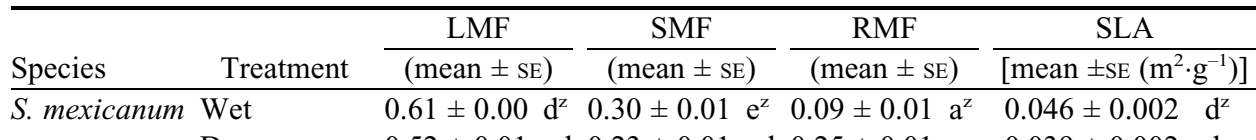
Dry $\quad 0.52 \pm 0.01$ cd $0.23 \pm 0.01$ cd $0.25 \pm 0.01$ e $0.039 \pm 0.002$ d Nonirrigation $0.46 \pm 0.02$ bc $0.20 \pm 0.01$ bc $0.34 \pm 0.02$ de $0.021 \pm 0.001$ bc $\begin{array}{llllllll}\text { Wet } & 0.58 \pm 0.02 \mathrm{~d} & 0.20 \pm 0.01 & \mathrm{~b} & 0.09 \pm 0.01 \mathrm{a} & 0.017 \pm 0.001 & \mathrm{ab}\end{array}$ Dry $\quad 0.60 \pm 0.01 \mathrm{~d} \quad 0.12 \pm 0.00$ a $\quad 0.27 \pm 0.01 \mathrm{~cd} \quad 0.016 \pm 0.000$ a Nonirrigation $0.48 \pm 0.01$ c $0.11 \pm 0.00$ a $0.41 \pm 0.01$ e $0.016 \pm 0.000$ a Wet $\quad 0.40 \pm 0.01$ bc $0.47 \pm 0.01 \mathrm{f} \quad 0.13 \pm 0.01$ b $0.024 \pm 0.001$ c species did not differ significantly ${ }^{{ }^{2}}$ Significant differences among means are indicated by different letters based on Dunnett-T3 at between treatments, but there were $P<0.05$.

significant differences between spe-

cies (Table 5). Initial carbon content

did not differ significantly between $S$. mexicanum $(0.20 \pm 0.01 \mathrm{~g})$, $S$. aizoon $(0.21 \pm 0.01 \mathrm{~g})$, and $Z$. matrella $(0.21 \pm 0.02 \mathrm{~g})$, but O. japonicus $(0.27 \pm 0.01 \mathrm{~g})$ had greater carbon content (Dunnett-T3 at $P<0.05)$. Carbon sequestration of the Sedum species was significantly influenced by the frequency of irrigation (Table 5). At the end of the experiment, carbon content of $Z$. matrella was similar to that of Sedum in the wet treatments, whereas $O$. japonicus was similar to that of Sedum in the dry treatments. The time course of whole-plant carbon content is shown in Fig. 4. Average carbon content increased across the study period.

Results of the growth analysis are shown in Table $6 . \mathrm{RGR}_{\mathrm{c}}$ of the two Sedum species was clearly affected by the difference in frequency of irrigation and was similar in each treatment. $\mathrm{NAR}_{\mathrm{c}}$ and $\mathrm{LAR}_{\mathrm{c}}$ of the two Sedum species were also influenced by the difference in frequency of irrigation, except for the $L A R_{c}$ of $S$. aizoon.

In the wet treatment, $S$. mexicanum and $S$. aizoon had the highest $\mathrm{RGR}_{\mathrm{c}}$ of the four species. Sedum mexicanum had the lowest $\mathrm{NAR}_{\mathrm{c}}$ of the four species, but its $\mathrm{LAR}_{\mathrm{c}}$ was more than double that of the others. Sedum aizoon had the second highest $\mathrm{NAR}_{\mathrm{c}}$ and $\mathrm{LAR}_{\mathrm{c}}$ in the wet treatment. In comparison, although Z. materella exhibited the highest $\mathrm{NAR}_{\mathrm{c}}$, its $\mathrm{RGR}_{\mathrm{c}}$ was lower than that of the two Sedum species because its $\mathrm{LAR}_{\mathrm{c}}$ was lower than that of Sedum in all treatments. Ophiopogon japonicus also had high $\mathrm{NAR}_{\mathrm{c}}$ and the lowest $\mathrm{LAR}_{\mathrm{c}}$ in this experiment, which resulted in $\mathrm{RGR}_{\mathrm{c}}$ being lower than that of Sedum in the dry treatment. The four plant species in the wet treatment had a significant correlation $(r=0.972, P<0.05)$ between $\mathrm{NAR}_{\mathrm{c}}$ and photosynthetic rate $\left(25^{\circ} \mathrm{C}, 1000 \mu \mathrm{mol} \cdot \mathrm{m}^{-2} \cdot \mathrm{s}^{-1}\right)$. In addition, LAR is commonly known as an index derived from LMF and SLA in growth analyses. There was significant correlation $(r=$ $0.959, P<0.01)$ between $\mathrm{LAR}_{\mathrm{c}}$ and the product of LMF and SLA in all species and treatments.

$\mathrm{GRC}_{\mathrm{NARc}}$ and $\mathrm{GRC}_{\mathrm{LARc}}$ of $S$. mexicanum were about 0.7 and 0.3 , respectively, in all comparisons (Table 7). This result indicates that $70 \%$ of a change in $\mathrm{RGR}_{\mathrm{c}}$ (competence for carbon sequestration) was due to changes in $\mathrm{NAR}_{\mathrm{c}}$ and $30 \%$ was due to changes in $\mathrm{LAR}_{\mathrm{c}}$. In contrast, $\mathrm{GRC}_{\mathrm{NARc}}$ of $S$. aizoon was about 0.95 , so competence for carbon sequestration was strongly affected by a change in $\mathrm{NAR}_{\mathrm{c}}$. Sedum aizoon did not differ in
Table 5. Mean values $(n=6)$ for carbon concentration and carbon content of two Sedum species (Sedum mexicanum and Sedum aizoon) in wet treatment (plants supplied nutrient solution every day), dry treatment (plants supplied nutrient solution once per week), and nonirrigation treatment [plants only supplied nutrient solution at the start of the experiment $(0 \mathrm{~d})]$ at the end of the experiment (49 d), and those of two green roof plants (Zoysia matrella and Ophiopogon japonicus) in the wet treatment.

\begin{tabular}{|c|c|c|c|c|}
\hline \multirow[b]{2}{*}{ Species } & \multirow[b]{2}{*}{ Treatment } & \multirow{2}{*}{$\frac{\mathrm{C}}{[\text { mean } \pm \mathrm{SE}(\%)]}$} & \multicolumn{2}{|c|}{ Carbon content } \\
\hline & & & \multicolumn{2}{|c|}{$[$ mean \pm SE (g/plant)] } \\
\hline \multirow[t]{3}{*}{ S. mexicanum } & Wet & $37.4 \pm 0.4 a^{2}$ & $3.4 \pm 0.2$ & $\mathrm{C}^{\mathrm{z}}$ \\
\hline & Dry & $37.4 \pm 0.3 \mathrm{a}$ & $1.1 \pm 0.0$ & B \\
\hline & Nonirrigation & $37.9 \pm 0.5 \mathrm{abc}$ & $0.3 \pm 0.0$ & A \\
\hline \multirow[t]{3}{*}{ S. aizoon } & Wet & $38.8 \pm 0.3 \mathrm{bc}$ & $3.7 \pm 0.2$ & $c^{\prime z}$ \\
\hline & Dry & $39.7 \pm 0.2 \mathrm{~cd}$ & $0.9 \pm 0.0$ & $b^{\prime}$ \\
\hline & Nonirrigation & $38.8 \pm 0.4 \mathrm{abcd}$ & $0.3 \pm 0.0$ & $a^{\prime}$ \\
\hline Z. matrella & Wet & $42.6 \pm 0.1 \mathrm{e}$ & $3.2 \pm 0.2$ & \\
\hline O. japonicus & Wet & $40.3 \pm 0.2 \mathrm{~d}$ & $0.8 \pm 0.1$ & \\
\hline
\end{tabular}

${ }^{\mathrm{z}}$ Significant differences among means are indicated by different letters based on Dunnett-T3 at $P<0.05$.

SLA among treatments, which may be related to this result (Table 4). Thus, variation in carbon sequestration for different below-ground resources seemed to be mainly caused by physiological responses.

The $\mathrm{NAR}_{\mathrm{c}}$ and $\mathrm{LAR}_{\mathrm{c}}$ results were consistent with the results for photosynthetic rates and biomass allocation. This finding suggested that growth analysis reveals the relevance of physiological $\left(\mathrm{NAR}_{\mathrm{c}}\right)$ and morphological $\left(\mathrm{LAR}_{\mathrm{c}}\right)$ traits and competence for carbon sequestration $\left(\mathrm{RGR}_{\mathrm{c}}\right)$. Thus, it became clear that the appropriate water and nutrient regime could elevate the competence for carbon sequestration in a Sedum green roof as a result of physiological and morphological responses.

Moreover, there is an suggestion that Sedum has higher competence for carbon sequestration than a $\mathrm{C}_{4}$ plant $(Z$. matrella) in appropriate below-ground resource (water and nutrient) conditions for Sedum species, and even a Sedum green roof with a low frequency of irrigation or rain events may show higher carbon sequestration than another green roof plant $(O$. japonicus). 

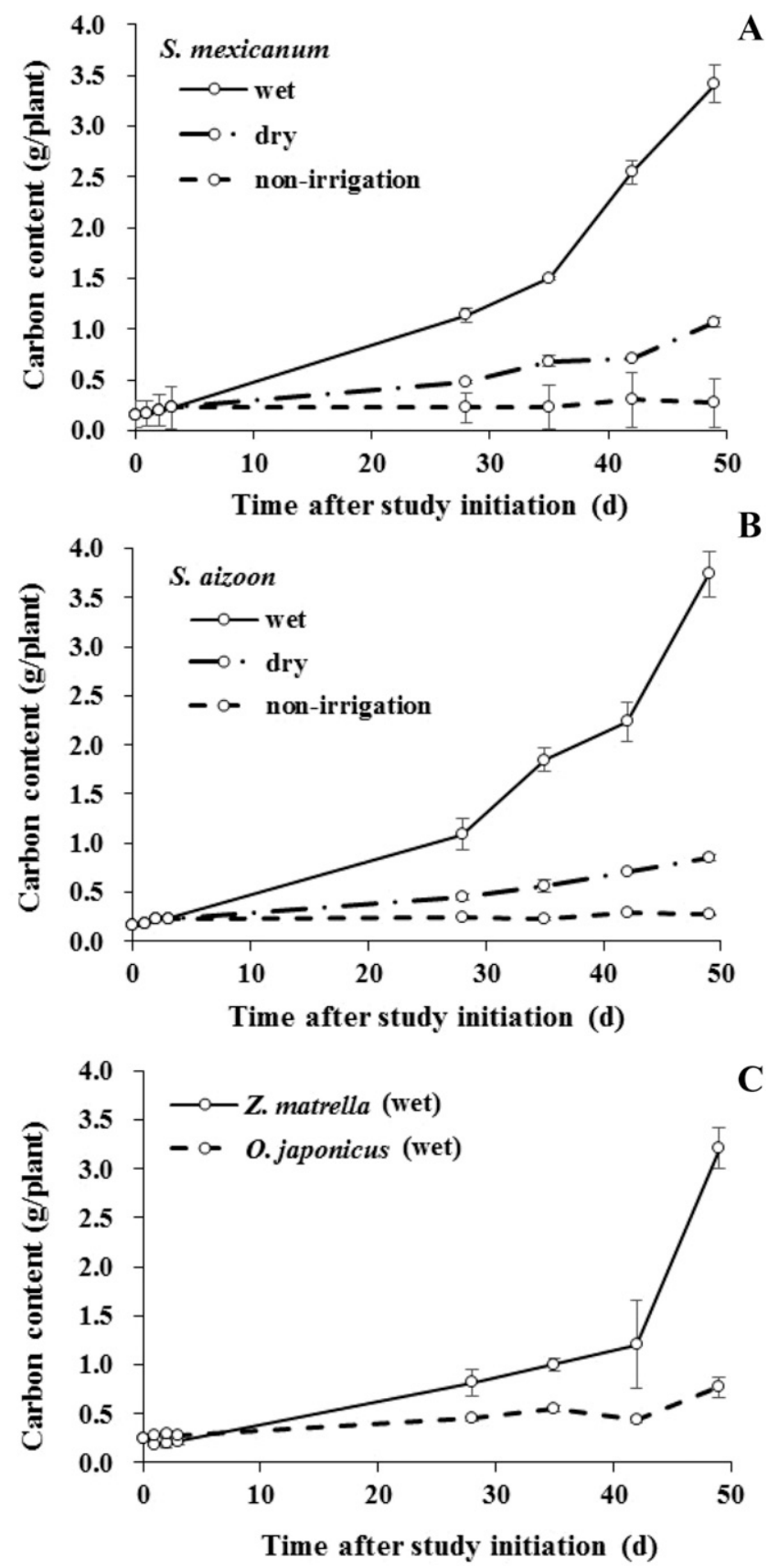

Fig. 4. Time course of mean values for carbon content of two Sedum species [(A) Sedum mexicanum, (B) Sedum aizoon] in wet treatment (plants supplied nutrient solution every day), dry treatment (plants supplied nutrient solution once per week), and nonirrigation treatment (plants only supplied nutrient solution at the start of the experiment [0 d]), and those of two other green plants [(C) Zoysia matrella and Ophiopogon japonicus) in wet treatment. Means $\pm \mathrm{SE}$ are presented $(n=3$, except for after $3 d$ and after $49 d$ where $n=6)$.

From the standpoint of application to actual green roofs, this study did not cover all green roof conditions (e.g., wind speed, high and low temperatures, light intensities, and nutrient conditions) which may have led to different growth of plants as compared with those in actual extensive green roofs. Thus, for other environmental conditions and plant growth stages, the relevance of physiological and morphological traits and environmental benefits should be studied further. Our results will serve as a baseline of the physiological and morphological traits and
Table 6. Relative $\mathrm{C}$ sequestration rate per whole-plant $\mathrm{C}$ content $\left(\mathrm{RGR}_{\mathrm{c}}\right)$, net assimilation rate $\left(\mathrm{NAR}_{\mathrm{c}}\right)$, and leaf area ratio per wholeplant $\mathrm{C}$ content $\left(\mathrm{LAR}_{\mathrm{c}}\right)$ of two Sedum species (Sedum mexicanum and Sedum aizoon) in wet treatment (plants supplied nutrient solution every day), dry treatment (plants supplied nutrient solution once per week), and nonirrigation treatment [plants only supplied nutrient solution at the start of the experiment $(0 \mathrm{~d})]$ and those of two green roof plants (Zoysia matrella and Ophiopogon japonicus) in the wet treatment.

\begin{tabular}{|c|c|c|c|c|}
\hline Species & Treatment & $\frac{\mathrm{RGR}_{\mathrm{c}}}{\text { (per d) }}$ & $\frac{\mathrm{NAR}_{\mathrm{c}}}{\left(\mathrm{g} \cdot \mathrm{m}^{-2} \cdot \mathrm{d}^{-1} \mathrm{C}\right)}$ & $\frac{\mathrm{LAR}_{\mathrm{c}}}{\left(\mathrm{m}^{2} \cdot \mathrm{g}^{-1} \mathrm{C}\right)}$ \\
\hline \multirow[t]{3}{*}{ S. mexicanum } & Wet & 0.062 & 1.07 & 0.059 \\
\hline & Dry & 0.035 & 0.73 & 0.048 \\
\hline & Nonirrigation & 0.008 & 0.26 & 0.031 \\
\hline \multirow[t]{3}{*}{ S. aizoon } & Wet & 0.062 & 2.52 & 0.024 \\
\hline & Dry & 0.031 & 1.26 & 0.024 \\
\hline & Nonirrigation & 0.006 & 0.29 & 0.022 \\
\hline Z. matrella & Wet & 0.053 & 3.34 & 0.017 \\
\hline O. japonicus & Wet & 0.019 & 1.34 & 0.014 \\
\hline
\end{tabular}

Table 7. Growth response coefficients (GRC) of net assimilation rate $\left(\mathrm{NAR}_{\mathrm{c}}\right)$ and leaf area ratio per whole-plant $\mathrm{C}$ content $\left(\mathrm{LAR}_{\mathrm{c}}\right)$ in two Sedum species (Sedum mexicanum and Sedum aizoon) between wet and dry, wet and nonirrigation, and dry and nonirrigation treatments [wet treatment: plants supplied nutrient solution every day, dry treatment: plants supplied nutrient solution once per week, nonirrigation treatment: plants only supplied nutrient solution at the start of the experiment $(0 \mathrm{~d})]$.

\begin{tabular}{llcc}
\hline Species & \multicolumn{1}{c}{ Comparison } & GRC $_{\mathrm{NARc}}$ & $\mathrm{GRC}_{\mathrm{LARc}}$ \\
\hline S. mexicanum & Wet and dry & 0.68 & 0.36 \\
& Wet and nonirrigation & 0.69 & 0.31 \\
S. aizoon & Dry and nonirrigation & 0.69 & 0.29 \\
& Wet and dry & 0.99 & 0.01 \\
& Wet and nonirrigation & 0.94 & 0.05 \\
& Dry and nonirrigation & 0.92 & 0.07 \\
\hline
\end{tabular}

carbon sequestration of green roof plants, and contribute to more suitable design and maintenance of vegetation in green roofs.

\section{Conclusions}

This study compared physiological and morphological traits of four green roof plants and discussed the influence of these traits on their environmental benefits in controlled conditions. In wet and increased nutrient conditions, $S$. mexicanum and $S$. aizoon exhibited the $\mathrm{C}_{3}$ photosynthetic pathway, and their LMF significantly increased in comparison with the dry and nonirrigation treatments. Consequently, transpiration rates and competence for carbon sequestration $\left(\mathrm{RGR}_{\mathrm{c}}\right)$ of the two Sedum species were higher than those of $Z$. matrella and $O$. japonicus in our experiment.

Although this study do not cover all green roof conditions and plant growth stages, our results serve as a baseline of the physiological and morphological traits and carbon sequestration of green roof plants. In addition, growth analysis performed on plant carbon content enabled the relevance of physiological $\left(\mathrm{NAR}_{\mathrm{c}}\right)$ and morphological $\left(\mathrm{LAR}_{\mathrm{c}}\right)$ traits and competence for carbon sequestration $\left(R_{G} R_{c}\right)$ in green roof plants to be understood more clearly. This analysis method could apply to other experiments and green plants. Our results 
and analysis method will contribute to more suitable design and maintenance of vegetation in green roofs.

\section{Literature Cited}

Adamsen, F.G., P.J. Pinter, E.M. Barnes, R.L. LaMorte, G.W. Wall, S.W. Leavitt, and B.A. Kimball. 1999. Measuring wheat senescence with a digital camera. Crop Sci. 39(3):719-724.

Blanusa, T., M.M.V. Monteiro, F. Fantozzi, E. Vysini, Y. Li, and R.W.F. Cameron. 2013. Alternatives to Sedum on green roofs: Can broad leaf perennial plants offer better 'cooling service'? Build. Environ. 59:99-106.

Butler, C. and C.M. Orians. 2011. Sedum cools soil and can improve neighboring plant performance during water deficit on a green roof. Ecol. Eng. 37(11):1796-1803.

Chen, C.F. 2013. Performance evaluation and development strategies for green roofs in Taiwan: A review. Ecol. Eng. 52(1):51-58.

Dimoudi, A. and M. Nikolopoulou. 2003. Vegetation in the urban environment: Microclimatic analysis and benefits. Energy Build. 35(1):69-76.

Durhman, A.K., D.B. Rowe, and C.L. Rugh. 2006. Effect of watering regimen on chlorophyll fluorescence and growth of selected green roof plant taxa. HortScience 41:1623-1628.

Feng, C., Q. Meng, and Y. Zhang. 2010. Theoretical and experimental analysis of the energy balance of extensive green roofs. Energy Build. 42(6):959-965.

Garland, J.A. 1977. The dry deposition of sulphur dioxide to land and water surfaces. Proc. R. Soc. Lond. A 354:245-268.

Getter, K.L., D.B. Rowe, and J.A. Andresen. 2007. Quantifying the effect of slope on extensive green roof stormwater retention. Ecol. Eng. 31(4):225-231.

Getter, K.L., D.B. Rowe, G.P. Robertson, B.M. Cregg, and J.A. Andresen. 2009. Carbon sequestration potential of extensive green roofs. Environ. Sci. Technol. 43(19):7564-7570.

Gravatt, D.A. and C.E. Martin. 1992. Comparative ecophysiology of five species of Sedum (Crassulaceae) under well-watered and drought-stressed conditions. Oecologia 92(4):532-541.

Hunt, R. 1982. Plant growth curves. The functional approach to plant growth analysis. Edward Arnold, London, UK.

Kadas, G. 2006. Rare invertebrates colonizing green roofs in London. Urban Habitats 4(1):66-86.

Lambers, H., M.L. Cambridge, H. Konings, and T.L. Pons. 1989. Causes and consequences of variation in growth rate and productivity of higher plants. SPB Academic Publ., The Hague, The Netherlands.

Lee, H.S.J. and H. Griffiths. 1987. Induction and repression of CAM in Sedum telephium L. in response to photoperiod and water stress. J. Expt. Bot. 38(5):834-841.

Lin, Y.J. and H.T. Lin. 2011. Thermal performance of different planting substrates and irrigation frequencies in extensive tropical rooftop greeneries. Build. Environ. 46(2):345-355.
Lundholm, J., S. Tran, and L. Gebert. 2015. Plant functional traits predict green roof ecosystem services. Environ. Sci. Technol. 49(4): 2366-2374.

Nobel, P.S. 1991. Achievable productivities of certain CAM plants: Basis for high values compared with $\mathrm{C}_{3}$ and $\mathrm{C}_{4}$ plants. New Phytol. 119(2):183-205.

Oberndorfer, E., J. Lundholm, B. Bass, R.R. Coffman, H. Doshi, N. Dunnett, S. Gaffin, M. Köhler, K.K.Y. Liu, and B. Rowe. 2007. Green roofs as urban ecosystems: Ecological structures, functions, and services. Bioscience 57(10):823-833.

Poorter, H. and O. Nagel. 2000. The role of biomass allocation in the growth response of plants to different levels of light, $\mathrm{CO}_{2}$, nutrients and water: A quantitative review. Austral. J. Plant Physiol. 27(6): 595-607.

Poorter, H. and A. Van der Werf. 1998. Is inherent variation in RGR determined by LAR at low irradiance and by NAR at high irradiance? A review of herbaceous species, p. 309-336. In: H. Lambers, H. Poorter, and M.M. Van Vuren (eds.). Inherent variation in plant growth: Physiological mechanisms and ecological consequences. Backhuys Publ., Leiden, The Netherlands.

Sailor, D.J. 2008. A green roof model for building energy simulation programs. Energy Build. 40(8):1466-1478.

Sayed, O.H. 2001. Crassulacean acid metabolism 1975-2000, a check list. Photosynthetica 39(3):339-352.

Schneider, C.A., W.S. Rasband, and K.W. Eliceiri. 2012. NIH Image to ImageJ: 25 years of image analysis. Nat. Methods 9(7):671-675.

Solecki, W.D., C. Rosenzweig, J. Cox, L. Parshall, J. Rosenthal, and S. Hodges. 2006. Potential impact of green roofs on the urban heat island effect, p. 15-26. In: C. Rosenzweig, S. Gaffin, and L. Parshall (eds.). Green roofs in the New York metropolitan region: Research report. Columbia Univ. Ctr. Climate Systems Res., NASA Goddard Inst. Space Studies, New York, NY.

Susca, T., S.R. Gaffin, and G.R. Dell'Osso. 2011. Positive effects of vegetation: Urban heat island and green roofs. Environ. Pollut. 159:2119-2126.

Takakura, T., S. Kitade, and E. Goto. 2000. Cooling effect of greenery cover over a building. Energy Build. 31(1):1-6.

Van Mechelen, C., T. Dutoit, and M. Hermy. 2015. Adapting green roof irrigation practices for a sustainable future: A review. Sustainable Cities Soc. 19:74-90.

VanWoert, N., D.B. Rowe, J.A. Andresen, C.L. Rugh, and L. Xian. 2005. Watering regime and green roof substrate design affect Sedum plant growth. HortScience 40:659-664.

Villarreal, E.L. and L. Bengtsson. 2005. Response of Sedum green-roof to individual rain events. Ecol. Eng. 25:1-7.

Wong, N.H., D.K.W. Cheong, H. Yan, J. Soh, C.L. Ong, and A. Sia. 2003. The effects of rooftop garden on energy consumption of a commercial building in Singapore. Energy Build. 35(4):353-364.

Yang, J., Q. Yu, and P. Gong. 2008. Quantifying air pollution removal by green roofs in Chicago. Atmos. Environ. 42(31):7266-7273. 